\title{
Corpus
}

Archivos virtuales de la alteridad americana

Vol 2, No 2 | 2012

Julio / Diciembre 2012

\section{Relatos del conflicto interétnico: Francisco García de Piedrabuena contra los "charrúas y otros infieles, 1715}

Accounts of an ethnic conflict: Francisco Garcia Piedrabuena against "Charrúas and other heathens", 1715

\section{Sergio Hernán Latini}

\section{OpenEdition}

\section{Journals}

\section{Electronic version}

URL: http://journals.openedition.org/corpusarchivos/853

DOI: $10.4000 /$ corpusarchivos.853

ISSN: 1853-8037

\section{Publisher}

Diego Escolar

\section{Electronic reference}

Sergio Hernán Latini, « Relatos del conflicto interétnico: Francisco García de Piedrabuena contra los "charrúas y otros infieles, 1715 », Corpus [En línea], Vol 2, No 2 | 2012, Publicado el 30 diciembre 2012, consultado el 19 abril 2019. URL : http://journals.openedition.org/corpusarchivos/853 ; DOI : 10.4000/corpusarchivos.853

This text was automatically generated on 19 April 2019 


\section{Relatos del conflicto interétnico: Francisco García de Piedrabuena contra los "charrúas y otros infieles, 1715}

Accounts of an ethnic conflict: Francisco Garcia Piedrabuena against "Charrúas and other heathens", 1715

\section{Sergio Hernán Latini}

\section{EDITOR'S NOTE}

Fecha de recepción del original: 10/09/2012. Fecha de aceptación para publicación: 01/10/2012

1 Los primeros años del siglo XVIII fueron muy convulsionados en el litoral argentino y la Banda Oriental del Uruguay. Durante este período se realizaron tres campañas punitivas o "entradas al castigo de los infieles charrúas": una en 1702, otra en 1709 y la última en 1715.

2 Los charrúas eran un pueblo cazador-recolector nómade que, en esos años, habitaba y recorría las tierras situadas al este del río Paraná, es decir, la actual provincia de Entre Ríos, el sur de la provincia de Corrientes, y parte de lo que hoy constituye el territorio de la República Oriental del Uruguay. Desde esos espacios interactuaban tanto de forma pacífica como hostil con las ciudades hispanas de Santa Fe y Corrientes, la reducción de Santo Domingo Soriano y las misiones jesuitas de indios guaraníes. Los ataques y robos a los viajantes y comerciantes -incluso a las balsas o barcazas que navegaban los ríos Paraná y Uruguay-, el robo sistemático de ganado perteneciente a las estancias hispanas o a las misiones jesuíticas $\mathrm{y}$, sobre todo, el ataque a las reducciones guaraníes, especialmente a Nuestra Señora de los Reyes de Yapeyú, impulsaron las tres campañas punitivas mencionadas. 
3 En este trabajo presentamos el informe de la campaña llevada adelante por el maestre de campo Francisco García de Piedrabuena en 1715. Creemos que es un escrito interesante para dar a conocer, porque dicha campaña punitiva fue reiteradamente mencionada por diversos autores en base a referencias de otras fuentes. El presente manuscrito fue escrito precisamente por el propio comandante de la expedición y contiene sugestivos da-tos etnográficos para aquellos interesados en la historia indígena de la región ${ }^{1}$.

\section{Características del informe de Piedrabuena y su transcripción}

4 La fuente transcripta fue relevada en el marco de una investigación en curso sobre procesos de etnogénesis y reconfiguración étnica de los charrúas durante los siglos XVII y XVIII. La misma es una copia del informe que el maestre de campo Francisco García de Piedrabuena, comandante de la campaña punitiva contra los charrúas de 1715, elevó ante el gobernador de Buenos Aires, Baltasar García Ros, para comunicar todo lo sucedido durante la misma.

5 El escrito que presentamos se encuentra en la Colección De Ángelis, perteneciente a la Sección Manuscritos de la Biblioteca Nacional de Río de Janeiro (BNRJ). Otra copia del mismo la hemos localizado dentro del Fondo Documental Compañía de Jesús, correspondiente al Archivo General de la Nación, en Buenos Aires (AGN). Hemos cotejado y comparado ambas copias y comprobamos que son idénticas en casi todas las palabras ${ }^{2}$, excepto en el último párrafo en que, si bien cambian algunos de los vocablos, no se modifica el sentido o significado de lo que se quiere transmitir. Por el momento, ignoramos los motivos a los que se debe esta alteración en el último párrafo.

6 La BNRJ posee la Colección De Ángelis bajo el formato de microfilm. Dentro del microfilm MS 508 (23) y con la signatura I 29-3-94 se encuentra la copia transcripta en el presente trabajo. En el AGN pudimos consultar la otra copia original del mismo manuscrito al que hemos fotografiado con cámara digital. Este se encuentra en la Sala IX y bajo la signatura 6-9-5, como mencionamos, dentro del fondo documental Compañía de Jesús.

7 La copia de la BNRJ presenta nueve folios escritos por un solo lado. En cambio, la del AGN presenta siete folios, también escritos por un solo lado. Ambas se encuentran en buen estado de conservación -excepto el margen superior de seis de los folios de la copia del AGN que se encuentran rotos- y están fechadas el 12 de febrero de 1716 en la reducción San Carlos de indios guaraníes, perteneciente a la Compañía de Jesús.

Hemos transcripto el documento de forma completa, siguiendo en líneas generales las indicaciones propuestas por Branka Tanodi (2000). La ortografía ha sido modernizada para agilizar la lectura y se han mantenido los signos de puntuación originales, para no desvirtuar los posibles y diferentes significados que pudiera tener una frase. Solamente hicimos una excepción a esta norma: quitamos las comas que el copista escribió siempre anteponiendo a la conjunción copulativa "y" cuando estaba enumerando objetos, bienes, sucesos, etc.; porque consideramos que esta repetición continua de las comas entorpece la lectura dinámica del documento. Asimismo, siguiendo las sugerencias de Lidia Nacuzzi (1998), hemos mantenido en su grafía original los nombres propios de los personajes involucrados en el relato-tanto españoles como indígenas-, los lugares y los etnónimos o nombres de los diferentes grupos étnicos mencionados. 
9 La foliación que presentamos pertenece a la copia del AGN, completando las palabras faltantes - por rotura del papel o porque el copista las omitió- con la copia perteneciente a la BNRJ, presentando dichas palabras entre barras: "/ /". Asimismo, los vocablos escritos de diferente forma en la copia de BNRJ aparecerán con el mismo signo ortográfico al lado de la palabra con la grafía del AGN; por ejemplo: "Cala /Calâ/". Lo entrelineado o sobre-escrito lo pondremos entre guiones porque los paréntesis son utilizados por el propio copista. Aquellas palabras que agregamos porque el copista las omitió y, creemos que son necesarias para la comprensión del documento, las pondremos entre corchetes. Finalmente, aquellas aclaraciones que consideramos pertinentes las realizaremos con notas al pie de página.

10 En suma, en la transcripción realizada pretendemos que el texto permanezca fiel al original para ofrecer al lector "la posibilidad de utilizar ese documento sin necesidad de concurrir al repositorio donde se conserva" (Tanodi, 2000, p. 267).

\section{Contexto de producción del Informe de Piedrabuena}

11 Como dijimos, la transcripción que aquí presentamos es una copia del informe que escribió el maestre de campo Francisco García de Piedrabuena, vecino de la ciudad de Santa Fe, luego de retornar de la entrada "al castigo de los charrúas y otros infieles" de la que fue nombrado comandante por el gobernador de Buenos Aires. Dicha campaña punitiva se realizó entre noviembre de 1715 y enero de $1716^{3}$. El ejército que emprendió la marcha tras los charrúas estaba integrado mayoritariamente por indios guaraníes de las misiones jesuíticas ${ }^{4}$, acompañados por sus principales o caciques, que en estos papeles aparecen mencionados como "cabos de los indios". Completaban las huestes "cabos españoles" subalternos a Piedrabuena y padres jesuitas en calidad de capellanes.

Esta campaña punitiva de 1715 es descripta y analizada en antiguos escritos sobre la historia del Uruguay y del litoral argentino como los realizados por Francisco Bauzá ([1895] 1965), Manuel Cervera (1907) y Juan Faustino Sallaberry (1926). Sin embargo, especialistas más recientes en la temática como Eduardo Acosta y Lara ([1961] 2006), Ítala Basile Bécker ([1982] 2002) y Diego Bracco (2004) no la mencionan.

Los tres investigadores que estudiaron en primer término la entrada de 1715 , utilizaron como fuente principal de análisis el informe que realizó el padre jesuita Policarpo Dufo, que acompañaba como capellán al ejército expedicionario. Dicho documento fue transcripto y publicado por Manuel Ricardo Trelles en el tomo II de la Revista del Archivo General de Buenos Aires (1870)5. Es decir, el informe de Piedrabuena que aquí presentamos es una fuente inédita $y$, además, nunca fue trabajado por ningún estudioso del tema indígena del área en cuestión.

\section{El contenido del escrito de Piedrabuena}

14 Siguiendo el relato de Piedrabuena, observamos que la marcha del ejército expedicionario fue bastante penosa. Los guías o "prácticos de la tierra" -algunas veces miembros de las "tropas" que estaban vaqueando en la región y que fueron encontradas durante la marcha- o los "indios amigos" guenoas" que se les incorporaron en el paraje del Primer Palmar, erraban los caminos o el rastro dejado por los "indios infieles", conduciendo a las huestes españolas por terrenos faltos de pasto y agua para las cabalgaduras. Sumado a 
esto, muchos de los caballos habían comido la hierba venenosa del mío-mío, muriendo en consecuencia y constituyendo una pérdida considerable. A la larga, esta situación repercutió en toda la campaña. La falta de cabalgaduras disponibles y del alimento y el agua necesaria para las mismas, es un tópico recurrente en el escrito. Piedrabuena se vio forzado a determinar días de descanso y elegir lugares apropiados para el mismo ${ }^{8}$, teniendo que soportar las hostilidades indígenas mientras permanecían en cada sitio. En definitiva, era el cansancio de los caballos que quedaban en pie uno de los factores principales que obligó a la hueste española a emprender la retirada a principios de enero de 1716.

Asimismo, la marcha forzosa por cientos de leguas tras los rastros de los "indios enemigos" provocó una gran fatiga y cansancio tanto a los caballos como a los soldados españoles y guaraníes. Repetidas veces Piedrabuena llegó a parajes en donde habían estado las tolderías indígenas y encontró vestigios de las mismas pero sin sus habitantes. La información precedía al ejército español, los grupos indígenas muchas veces alertados se escapaban a campo traviesa'. En el momento en que finalmente logró encontrarse con los "indios enemigos" en Punta del Palmar, Piedrabuena decidió parlamentar por medio de un intérprete con los caciques "machados", "yaros" y "bojanes"10 para que se entregaran, repartiéndoles yerba y tabaco. Esta estrategia no dio resultado y durante la noche los indios estuvieron en gritería alrededor del campamento español. El resto de los días que duró la campaña, continuaron las hostilidades indígenas en forma de escaramuzas, como había sucedido hasta ese momento. El desaliento de las huestes y el cansancio de los caballos fue, como afirmamos, lo que determinó el fin de la expedición.

Creemos que la omisión de referencias a esta campaña en las investigaciones más actuales (Acosta y Lara [1961] 2006, Basile Bécker [1982] 2002 y Bracco 2004) se debe a que, como vimos, la misma no fue muy importante desde la perspectiva de los españoles, ya que no obtuvieron un resultado satisfactorio como el que pretendían cuando partieron de Yapeyú. El ejército expedicionario nunca pudo trabar un combate formal, como había ocurrido en la batalla del Yi de 1702 durante la cual los guerreros indígenas fueron diezmados (Bracco, 2004). Esta batalla seguramente estaba presente en la memoria colectiva de la sociedad colonial como hito del triunfo español contra los "indios infieles charrúas". A diferencia de la campaña de 1702, en 1715 la mayoría de los encuentros entre ambas facciones fueron simples escaramuzas en donde hubo pérdidas de hombres por ambas partes. No obstante, el resultado parece haber sido favorable a los charrúas, que lograron la retirada de los españoles.

17 Sin embargo, dentro del contexto de estas escaramuzas hay un hecho de suma importancia. Piedrabuena envía una patrulla en busca de un "indio infiel" que venía con una "tropa" que estaba vaqueando y que se había escapado cuando los espías de su ejército quisieron apresarlo. El maestre de campo envió un pequeño contingente compuesto por unos pocos españoles, indios guaraníes y guenoas. En plena marcha en busca del indio fugado, se toparon súbitamente con el cacique Carabí acompañado por "cuatro indios de su misma nación" y un niño guaraní que tenían como cautivo. Inmediatamente entraron en combate y en él ocurrió la muerte de dicho cacique.

Este hecho que aparece casi desapercibido en el in-forme de Piedrabuena es de gran importancia. Consideramos que Carabí era un cacique principal que había logrado aglutinar varios "grupos charrúas" para el ata-que y hostigamiento de viajeros, embarcaciones y troperos que salían en busca de ganado, y había mantenido en vilo a las misiones jesuíticas desde 1707 (Sallaberry, 1926). El padre Dufo, cuando describe este 
episodio en su informe, afirma que la partida de las huestes españolas mataron al "célebre y desdichado Carabí" ([1716] 1870, p. 249), creemos que estas palabras son indicio de que su prestigio como cacique había sido importante. Su muerte pudo haber sido uno de los motivos por el cual los caciques con los que posteriormente Piedrabuena parlamentó hubieran hecho caso omiso a lo que se les requería -entregarse para ser conducidos a prisión- y hubieran proseguido con sus hostilidades ante una exigencia obviamente inaceptable para ellos.

En suma, la campaña de Piedrabuena de 1715 puede parecer a simple vista un fracaso español debido a que nunca se entró en combate formal con los indios, las bajas en ambos bandos fueron escasas y parejas, y el derrotero español parece más bien un intento desesperado de encontrar las tolderías de los indios y buenos parajes con pasto y agua para las cabalgaduras. En definitiva, no se cumplieron las expectativas con que la hueste expedicionaria salió de Yapeyú. Sin embargo, consideramos que la muerte del cacique Carabí es un hecho singular que puede conllevar modificaciones dentro de la distribución de poder entre los caciques charrúas, como de las estrategias desarrolladas para hacer frente a la avanzada de la sociedad colonial en su territorio. Un estudio con otras fuentes del mismo período nos permitirá considerar la hipótesis presentada.

\section{¿Dos relatos de una misma campaña?}

20 En este apartado queremos reparar en las diferencias existentes entre la fuente utilizada por los estudiosos de la campaña punitiva contra los charrúas de 1715 -el informe del padre Policarpo Dufo- y la fuente inédita que transcribimos a continuación -el informe del maestre de campo Francisco García de Piedrabuena.

21 Comparando y cotejando los documentos, consideramos que ambos son complementarios. Es decir, la mayor parte del relato es coincidente y la mayoría de las diferencias son omisiones y afirmaciones de distinto tenor que realizó el autor del escrito. Esto se desprende de la perspectiva desde la cual escribió cada uno, las funciones que llevaban dentro del ejército expedicionario y a quién iba dirigido dicho informe. El padre Dufo le escribió a su superior religioso en las misiones dentro de la Compañía de Jesús y el maestre de campo Piedrabuena a su superior inmediato, el gobernador de Buenos Aires Baltasar García Ros, quien lo había comisionado para que realizara dicha campaña punitiva. Tal vez, el escrito del jesuita es más abundante en detalles que el del comandante militar. En resumen, ambos documentos no presentan diferencias sustanciales, excepto aquellas que mencionamos a continuación.

Dentro de la disimilitud de los relatos de ambos personajes, encontramos que la mayor parte de los fragmentos diferentes corresponden a omisiones que realizan uno $u$ otro autor dependiendo de las motivaciones personales que lo impulsaron a ocultar dicha información en su escrito. Estimamos que dos de las omisiones destacables que encontramos en el informe de Piedrabuena se pueden explicar con el hecho de que este comandante consideraba ambos sucesos - que comentaremos a continuación- como asuntos importantes que debían ser tratados aparte. Por este motivo, cuando comienza su relato realiza la aclaración de que reserva algunos artículos para dar cuenta de ellos al gobierno superior de Buenos Aires en autos distintos.

La primera de estas omisiones se debe a que Piedra-buena no escribió ni explicitó qué le contestó a Esteban Marcos de Mendoza, quien llegó al campamento enviado por el cabildo 
de Santa Fe para que se detuviera la expedición punitiva ${ }^{11}$, sino que simplemente se limitó a mencionar que respondió "lo que constaba de mi res-puesta en dicho auto" (f. 4). En cambio, Dufo explica que Piedrabuena le contestó a Mendoza que no obedecería al teniente de Santa Fe, porque él seguía órdenes e instrucciones del gobierno superior de Buenos Aires. La segunda omisión es respecto a una desobediencia que tuvo un sargento mayor del ejército expedicionario a las disposiciones y órdenes que le había dado el comandante Piedrabuena. El padre Dufo relata en cambio con mucho detalle cómo este sargento desobedeció las instrucciones y cómo tuvo que mediar él para templar los ánimos entre dicho subordinado y su jefe.

Consideramos que ambos hechos -la insubordinación de un militar español dentro del ejército y las cuestiones relativas a la jurisdicción de poder y control de territorio entre las ciudades de Santa Fe y Buenos Aires- eran asuntos muy importantes como para que Piedrabuena les dedicara autos separados. Todavía no hemos encontrado estos documentos $\mathrm{u}$ otros relacionados que permitan confirmar esta hipótesis.

Otras dos omisiones que encontramos en el escrito de Piedrabuena se deben a que éste pretendía presentarse ante su superior -el gobernador de Buenos Aires- como un buen jefe militar y negociador con los caciques indígenas, con un arte de la oratoria capaz de convencer al más empedernido infiel.

Piedrabuena relata que en el paraje denominado Primer Palmar se les agregaron quince "infieles guenoas amigos" que los acompañaron en el derrotero tras el enemigo. Luego, estos indios guenoas aparecen mencionados en varios sucesos, ya sea como guías en el camino, espías o avanzada del ejército. El padre Dufo describe también el encuentro con estos guenoas pero él refiere que se les repartió yerba, tabaco y una pieza de tejido de lana para que estos indios los guiaran por el camino. Es decir, lo que en el escrito de Piedrabuena pareciera ser una obediencia natural del indígena al español, omite u oculta una negociación previa.

La siguiente omisión tiene un tenor similar. La misma se refiere al momento en que finalmente las huestes españolas se encontraron con los indios infieles -que continuamente aparecen mencionados en ambos escritos como "el enemigo"- luego de muchos días de marcha frustrada. Como vimos, Piedrabuena llamó a los caciques a parlamentar para que se rindieran y en sus propias palabras, "para suavizar la materia", les repartió yerba y tabaco (f. 5). Sin embargo, el padre Dufo indica que los caciques infieles fueron quienes le pidieron al comandante yerba y tabaco mientras conversaban. En este suceso creemos que nuevamente Piedrabuena pretende aparentar ser un buen negociador ante su superior. Es decir, en su relato él se presenta como el líder generoso que ofrece regalos para suavizar a los caciques y que de esta manera acaten sus demandas, cuando en realidad son los caciques los que piden estos bienes al negociar.

Otra de las diferencias entre ambos documentos es cuando hacen referencia al momento en que Piedrabuena realiza una junta de guerra con todos los cabos españoles e indios guaraníes de su ejército el día 2 de enero de 1716, para decidir si se continuaba la campaña o si se emprendía la retirada. Luego del debate se decidió regresar a las misiones jesuíticas porque las cabalgaduras que habían sobrevivido estaban agotadas por la marcha y la falta de pastos y agua. Las huestes españolas se encontraban en las márgenes occidentales del río Uruguay frente a la reducción de Santo Domingo Soriano. En la junta de guerra se consideraron dos opciones para el regreso. La primera consistía en cruzar el río Uruguay, descansar unos días en la reducción y continuar la marcha desde esa banda del río. La segunda era retornar desde el sitio donde se hallaban. Luego de escuchar los 
pareceres de los "cabos", en su mayoría guaraníes, se decidieron por no cruzar el río porque los caballos estaban tan cansados que no iban a poder pasar a nado "río tan anchuroso" (f. 6). Piedrabuena menciona en pocas líneas esta junta de guerra, sin embargo el padre Dufo le dedica más de dos páginas a este asunto, en un relato con pormenorizados detalles. Creemos que esta diferencia sustancial se debe a que fue suya la propuesta de pasar a la otra banda del río Uruguay y que dicha consideración no fue tenida en cuenta. De hecho, previamente a la junta de guerra, él fue designado por Piedrabuna para cruzar el río hacia la reducción de Santo Domingo Soriano para negociar con el corregidor de la misma con el fin de obtener provisiones para el ejército y embarcaciones para cruzar el río. Las últimas líneas de su escrito las utiliza para manifestar que fue un gran error no haber cruzado el río Uruguay para regresar por las tierras de la otra banda, por el hostigamiento que fue recibiendo el ejército de parte de los "indios infieles" en su camino de retorno, encontrando de vez en cuando a algún indio guaraní de la avanzada muerto por las flechas enemigas. Dufo siguió defendiendo su propuesta y en cierta forma achacaba a Piedrabuena no haberlo escuchado.

Una omisión importante que encontramos en el relato del padre Dufo es un interrogatorio que realizó Piedra-buena a unos indios que estaban en la reducción de Santo Domingo Soriano y que habían sido vistos entre los "infieles" unos días antes. Ignoramos los motivos por los cuales el jesuita no describe este interrogatorio. Una explicación plausible puede ser que en el momento en que Piedrabuena interrogó a estos indios, Dufo se encontraba en la otra banda del río Uruguay, negociando con el corregidor de Santo Domingo Soriano. Más allá de los motivos que lo llevaron a no describir el interrogatorio, para nosotros el hecho de que indios reducidos se encontraran entre "infieles" es un indicador de lo permeables que eran los límites sociales entre los indígenas. Tanto podían estar entre los "charrúas infieles" buscados por el español para castigarlos, como podían estar viviendo en una reducción de "indios amigos del español", comerciando o negociando, o en busca de información.

Por último, encontramos entre las dos narraciones analizadas una diferencia que puede parecer mínima pero creemos que implica un detalle de gran valor etnográfico. Cuando el ejército expedicionario estaba acampando en el paraje de Gena, al anochecer los guenoas salieron al encuentro de tres indios yaros -Dufo dice indios enemigos sin explicitar ningún etnónimo- que habían ido a reconocer el campamento enemigo. Los guenoas "flecharon" a uno de los yaros, apresaron a otro, y el tercero logró escapar. El indio yaro apresado fue interrogado y según Piedrabuena era un cacique de ese grupo étnico. El padre Dufo, afirmó sin embargo que dicho individuo era "su predicante y adivino"([1716] 1870, p. 251). Esta descripción realizada por el jesuita nos abre una serie de interrogantes. ¿Era este personaje un chamán? Por lo que podemos deducir de los términos que utiliza Dufo para referirse a este sujeto consideramos que esto es probable, porque los jesuitas estaban avezados en reconocer entre la sociedad indígena estos personajes a quienes combatían con todo ahínco. Sin embargo, otra posibilidad que consideramos es que el cacique oficiara también de chamán, detentando una misma persona dos estatus diferentes. En estos momentos no estamos en condiciones de sostener ninguna de las dos opciones, esperamos encontrar en otras fuentes información etnográfica que nos ayude a dilucidar esta problemática. 


\section{Recapitulando}

31 La campaña punitiva al castigo de los "charrúas y de-más infieles" llevada a cabo por el maestre de campo Francisco García de Piedrabuena en 1715 se realizó dentro del contexto de una serie de hechos violentos a principios del siglo XVIII en el litoral argentino y la Banda Oriental del Uruguay.

Como mencionamos, las huestes hispanas conforma-das por soldados guaraníes, algunos españoles y padres jesuitas como capellanes, partieron de la reducción de Yapeyú en noviembre de 1715. Este ejército realizó una penosa marcha por tierras escasas de pastos y agua fresca donde sus caballos no pudieron recomponerse y recuperar las fuerzas, eludiendo al "enemigo". Este estaba formado por grupos étnicos pertenecientes a tres "naciones" diferentes, es decir, grupos a los cuales Piedra-buena denomina e identifica como "yaros", "bojanes" y "machados". La información precedía al ejército español que siempre llegó a las tolderías momentos después que los "indios infieles" escaparan. Estos últimos prefirieron la táctica del hostigamiento constante y la estrategia de no entrar en combate formal con las huestes expedicionarias, sino realizar escaramuzas furtivas, lo cual fue debilitando poco a poco las energías del ejército colonial. Piedrabuena parlamentó con los caciques para que se entregaran -o negoció una honrosa rendición de los mismos- lo cual no fue aceptado de ninguna manera por ellos, continuando entonces con su estrategia hostil. Finalmente, en una junta de guerra, los cabos principales aconsejaron al comandante Piedrabuena, retornar a las misiones jesuíticas, ya que el ejército se encontraba sumamente agotado y con una merma considerable de cabalgaduras.

El resultado de esta campaña expedicionaria sin dudas no fue el esperado por la sociedad hispano-criolla. Sin embargo, nosotros consideramos como un hecho trascendente que, en una refriega, el cacique Carabí haya perdido la vida. La muerte de un cacique principal podría implicar modificaciones en la sociedad indígena en los años venideros. Esta es una de las líneas de investigación que proseguiremos con la búsqueda de otras fuentes que puedan ayudarnos a esclarecer esta hipótesis.

Consideramos que las campañas punitivas que se realizaron a principios del siglo XVIII se deben a una avanzada más agresiva del Estado colonial a un territorio que aún no controlaba efectivamente (Bracco, 2004). Hemos conceptualizado esta área como un "espacio de frontera", es decir: un espacio permeable y poroso, con frecuente comunicación e intercambios pacíficos o conflictivos entre la sociedad europea y las poblaciones indígenas, con procesos de mestizaje cultural, social, político y económico (Nacuzzi, 2010).

35 La fuente que aquí transcribimos es un claro ejemplo de los diferentes procesos que se estaban gestando dentro de este espacio de frontera. Hostilidades, negociaciones e intercambios de bienes e información entre españoles, mestizos, "tropas" que vaqueaban e indígenas con diferentes etnónimos: "guenoas", "yaros", "machados", "bojanes", "tapes" y "charrúas". Encontramos "indios infieles" vaqueando junto con "tropas" formadas y dirigidas por españoles, "indios amigos" que se encontraban entre los "infieles" y que luego fueron vistos dentro de la reducción de Santo Domingo Soriano, "guenoas" que colaboraron con el ejército colonial -más allá de que ellos también estaban catalogados como "infieles"-, españoles -o mestizos- que informaron en las tolderías enemigas el avance del ejército con bastante anticipación para que los indios 
puedan escaparse, "indios infieles" que parlamentan o negocian con el europeo a cambio de bienes manufacturados como yerba y tabaco... Todos estos acontecimientos representan diversas y múltiples aristas de procesos ocurridos en ámbitos fronterizos, lo cual es de por sí complejo y nos demuestra la flexibilidad de las categorías sociales y la porosidad del espacio que permite que distintos actores sociales y bienes discurran sin ningún tipo de traba u obstáculo alguno.

El informe de Piedrabuena que transcribimos constituye una fuente inédita que puede complementar aquellas que fueron más utilizadas por los investigadores para analizar el mismo período histórico, como el informe del padre Policarpo Dufo. El ejercicio de comparación que realizamos en este trabajo demuestra lo importante que es la triangulación de documentos diferentes para poder entender cabalmente un proceso sociohistórico complejo. Finalmente, consideramos que es una fuente con valiosos datos etnográficos -nombres de caciques, etnónimos, número de toldos, ubicaciones de las tolde-rías, relaciones interétnicas, etc. - que pueden sernos de mucha utilidad en estudios futuros sobre estos grupos étnicos.

\section{Transcripción del manuscrito}

Tanto del Informe que hizo al Gobernador de Buenos Aires el Maestre de Campo Don Francisco García de Piedrabuena cuanto entró a castigar a los infieles el año de 1715. Buenos Aires Don Baltasar García Ros, sobre lo sucedido en la entrada al castigo de los infieles en 8 de noviembre de 1715./

[Folio 1]

[...] de Francisco García Piedrabuena [...] Gobernador de Buenos Aires en entrada del año 1715 [...] castigo de los infieles.

/ Muy Ilustre Señor Gobernador y Capitán General/

En este pueblo de San Carlos reducción de indios Tapes, que están a cargo de los religiosos de la Compañía de Jesús en la jurisdicción de la Trinidad Puerto de Buenos Aires. En 12 días del mes de febrero de mil setecientos dieciséis años el Maestre de Campo Francisco García de Piedrabuena, Cabo Comandante este de los españoles, e indios tapes, que salieron al castigo de los charrúas y otros infieles, que con sus insultos, muertes y robos inquietaban la tierra e impedían los caminos de ambos ríos Paraná y Uruguay. Dijo que por cuanto en el despacho expedido en el Puerto de Buenos Aires por el Gobierno Superior de él, confirmado por el Señor Maestre de Campo Don Baltasar García Ros Gobernador y Capitán General de dicho puerto; en el cual que se le daba comisión y mandato para dicha expedición y pacificación de la tierra y castigo de los infieles, con el título de Maestre de Campo de la susodicha gente; se le mandaba también, que fenecida y acabada dicha expedición, diese cuenta por autos de lo en ella sucedido. Por tanto, obedeciendo dicho despacho de su Señoría, y cumpliendo fielmente lo en el contenido, mandaba y mandó se diese cuenta de lo sucedido en dicha expedición desde sus principios, hasta sus fines a dicho Gobierno Superior. Lo cual hacía e hizo en la forma y manera siguiente. Reservando, (como reservo) ${ }^{12}$ algunos pocos artículos para dar de ellos cuenta al dicho Gobierno Superior en otros autos distintos. El día ocho de noviembre del año próximo pasado de mil setecientos quince, en el paraje de Guabirabí, vulgarmente así llamado, (que yo llamé Santiago) términos de los Santos Reyes, que llaman del Yapeyú, 
hice reseña general de la gente y registro general de las armas y cabalgaduras, siendo todo de mi aprobación y satisfacción; siendo la gente toda de la mejor y más escogida; y lo demás del avío en abundancia todo, sin que los Reverendos Padres me negasen cosa alguna de las que yo insinué para el mejor logro de la dicha expedición. Y habiendo desde susodicho paraje dado principio a la marcha, y a los cinco días llegado al río que vulgarmente llaman el Mocoreta; desde allí despaché al Capitán Juan de Arriola, con doce soldados a recorrer la tierra, quienes encontraron con la gente del Sargento Mayor Marques Montiel, por estar, como entonces estaban, vaqueando. Y uno de la dicha tropa, llamado Juan Fernández, natural de las Corrientes dio noticia (aunque no del todo cierta) al Capitán Arriola donde pudiesen estar a la sazón los infieles; y se ofreció a servirnos de guía, Fernández. El cual habiendo venido me repitió la misma oferta, de que sirviéndonos de guía, nos conduciría a donde juzgaba estar el enemigo, y aún más, que iría delante a explorar el camino de la tierra y el sitio. Como con efecto lo ejecutó, yendo a esta facción solo, por no dar sospecha alguna al enemigo, si llevase alguno en su compañía; prometiéndome de volver con la noticia al paraje que llaman Lucas, $u$ otro que dicen Diego Martínez. Este mismo Juan Fernández (como práctico de toda la tierra) antes de partirse, nos previno por donde habíamos de conducir la marcha. Más dicho Fernández, ultra de no volver a vernos más, nos fue de grave perjuicio. Con el derrotero verbal que nos señalo. Pues por todo el camino, que nos había señalado, no hallamos pasto alguno para las cabalgaduras. Ya no habernos Dios depara-do al Capitán Phelipe Toledo, hubiera sin duda alguna aparecido [en] nuestro campo. Quien nos advirtió del camino; y él mismo nos condujo a él, y guiados del susodicho llegamos al primer palmar, donde estaba el Sargento Mayor Francisco Carvallo con la gente del colegio de la Compañía de Jesús de Santa Fe, cuyo capataz era dicho Toledo. Allí adquirimos noticia (aunque tampoco no muy cierta) donde podían hallarse los dichos enemigos. Porque aunque poco habían estado allí, como ciento y un toldos de ellos, no se sabía de cierto donde se hubiesen partido. En este paraje se nos agregaron quince infieles Guenoas amigos, con quienes juntos, marchamos en busca del enemigo. A dos, o tres jornadas topamos con Ramón Sacafuego, quien nos dio noticia de cómo en un paraje llamado Cala /Calâ/, estaba arranchado el Capitán de los infieles Caravi con veinticinco toldos; y que más acá, como cuatro o cinco leguas en otro corral llamado la laguna de la Sentella, había otros ocho toldos de la misma parcialidad; y habiendo ido en demanda de las dos tolderías, me trajeron noticia, como había dos toldos de infieles en el paso del río vulgarmente llamado Gualeguaychu agregados a la tropa de Don Antonio de Vera con cuya noticia despaché luego allá al Capitán Marcelo Martínez acompañado de otro español, de un pardo, y de seis guenoas, con orden mía que los prendiesen; y en caso de resistirse se valiesen de la armas. Lo cual ejecutaron fielmente. Entonces un indio llamado Ignacio Lezcano, se puso en defensa; pero habiéndole hablado el Cabo, se entregó. Otro de nación Boan, no obstante que se puso en fuga, fue apresado con dos mujeres, y una criatura, dicho indio Bohan /Bojan/ volvió a hacer fuga; mas los indios guenoas le quitaron luego la vida. Dicho Cabo volvió luego al ejército a darme 
cuenta de todo, y a guiarnos para otro paso. Y habiendo dado algún/ descanso así de la gente, como a la caballada, marché, luego, adonde estaban dichos infieles apresados; adonde la gente de Don Antonio de Vera nos dio noticia, como había dos toldos de infieles Bojanes, como dos leguas de allí, en un paraje llamado Xeña /Xenâ/, donde despache luego a los Capitanes Juan Arriola, y Marcelo Martínez, y Antonio Toledo con cincuenta tapes, y con un práctico de la tierra; y habiendo ido, sólo hallaron los vestigios de haber estado allí los infieles. Dispuse luego, que seis indios pasasen a la otra banda del río Gualeguaychu, para que estuviesen en centinela, mientras yo dividía el tercio en tres trozos. El uno que quedase con la caballada cansada y las cargas del avío; el otro que fuese con dos Cabos españoles; y el Reverendo Padre Antonio de Alarcón a la laguna de la Sentella, a donde los españoles de las tropas afirmaban haber algunos toldos de yaros y de Bojanes; y con el tercero ir yo a la toldería, que estaba en el paraje de Cala / Calâ/; y habiendo dado orden a los españoles y Cabos de los pueblos; dos indios de la espía me trajeron noticia de que un /indio/ infiel venía incorporado con la gente de Andrés Pintado; y que aunque los españoles cabos lo llamaban el receloso, no se atrevió a acercarse; antes si se retiraba hacia atrás. Viendo esto los indios tapes espías, le acometieron de repente para cogerlo; mas él se escapó de sus manos, pasando a nado el río hacia la banda donde yo estaba; y habiendo despachado luego algunos españoles de los que iban conmigo y algunos de las tropas, que allí estaban, con algunos indios tapes y guenoas en busca de dicho indio, dieron de repente con el indio infiel Caravi con otros cuatro de su nación y un guaranicito de ocho años del pueblo del Yapeyú; y habiéndose puesto en resistencia, mataron al dicho Caravi y a tres de sus compañeros, cogiendo al guaranicito. Al punto dispuse la marcha al sitio donde había sido muerto Caravi, dando orden que el otro tercio caminase a la laguna de la Sentella, enviando personas por parajes ocultos, que diesen noticia al otro tercio, para que se juntase con el primero; y yo caminé todo el día y toda la noche /hasta/ llegar al amanecer a la entrada del monte de Cala /Calâ/,donde determiné dejar la caballada que llevaba de reserva; y habiendo esperado que aclarase, para

/cercarlos; al tiempo de ejecutarlo, nos hallamos con toda la toldería,/ sin saberse el rastro por más de dos horas, que se hizo diligencia por él. En este sitio un indio de los nuestros me dio noticia de cómo había hallado tres indios de nuestras caballerizas, muertos y uno herido, y entre ellos el Capitán de San Nicolás. Acudí luego allá y conmigo el Reverendo Padre Policarpo a dar las providencias necesarias; y el herido examinado, dijo, que estando los difuntos mudando cabalgaduras, salieron de repente los infieles del monte, quienes les hirieron a él y le mataron a sus tres compañeros. Y luego vinieron los Guenoas, quienes dijeron que el rastro suyo iba hacia el lugar donde dejamos nuestra caballada y las cargas. Y luego proseguí tras ellos; y habiendo llegado a un lugar llamado Genâ, topé allí los dos tercios. A donde hice mansión aquella noche. El día siguiente, habiendo tomado lengua de los vaqueros, no supieron darme razón donde estaban los infieles. Ese mismo día cinco o seis guenoas dieron con tres yaros, flecharon al uno, y aprisionaron a un cacique. El cual atormentado, dijo, como un español barbón amulatado había dado noticia a los infieles, de cómo esa noche les habíamos de dar el avance; y como dichos infieles podían hurtándonos la vuelta hacernos algún daño (como lo hicieron) matando a los tres, que llevo referido; y después mataron luego al dicho indio cacique; y de todo esto nos enviaron a dar parte una india de su misma nación guenoa. Aquel día con consulta de los españoles y Cabos de los indios, determiné ir al Uruguay al paso de Vera, 
para el descanso de los caballos, que estaban rendidos, a donde llegué dentro de dos días; $\mathrm{y}$ a donde estuve cuatro y luego fue necesario ir costeando a buscar pasto para los animales y carne para los indios y en cada jornada me iba acercan-do más al enemigo. El día dieciocho de diciembre llegó a mi presencia y tercio el Capitán Don Esteban Marcos y Mendoza acompañado con diez soldados con bandera blanca desplegada, enviado por la Señoría del Cabildo y Señor Teniente de Santa Fe; y preguntado /lo/ que quería, me intimó un auto del Señor Teniente de aquella ciudad, en que me mandaba pena de seis mil pesos me retirase de la campaña; al cual respondí lo que constaba de mi respuesta al pie de dicho auto; y habiéndose ido, proseguí en busca de los enemigos, a quienes encontramos luego en el paraje llamado Punta del Palmar. Donde nos salieron en forma de escaramuza a usanza suya. Y por medio del intérprete, les mandé decir que parasen y se acercasen los caciques para oír el despacho que traía de su Señoría, lo cual hicieron algunos de ellos; y a los caciques de los machados - hablé- de parte de su Señoría, para que se apartasen de los yaros y Bojanes. Viendo era imposible el que se diesen a prisión, hice llamar al cacique llamado Pintado y otro llamado Don Thomas procurando suavizar la materia, les repartí yerba y tabaco; amonestándoles se juntasen los caciques a deliberar su entrega. Y habiendo quedado de hacerlo así, la respuesta fue, que los Bojanes y yaros a la noche comenzaron a dar carreras y gritos alrededor del real y se retiraron luego. El día siguiente hirieron a un indio de San Carlos, motivo para comenzar luego la guerra; pero tan a lo lejos que no podían lograr tiro contra [ilegible] todos nuestra infantería; y como los de a caballo lograsen algunos, se dieron a fuga. Procurando sacarnos al camino yeguas y toros cimarrones, para ver si estos con su ferocidad descomponían el trozo, o si el hambre, con que iban los indios, les compelía a desamparar sus sitios, viendo la carne a los ojos. Pero nada bastó para que gente tan bien disciplinada faltase a su obligación, penetrando luego los intentos del enemigo. Fue necesario luego parar para el descanso de la caballada. Allí, aquella noche, algunos gentiles se sintieron (quizás vinieron a probar nuestra vigilancia y cuidado) ${ }^{13} \mathrm{y}$ como esta estaba tan desvelada, no pudo lograr tiro alguno; ocupando toda la noche en tirar algunos tiros por donde se sentía, o sospechaba su presencia. El día siguiente los fui siguiendo por su propio rastro por tierras y pajonales inexplicables en que gasté cuatro días. Ellos saliendo a tierra limpia, por no mostrarnos sus pisadas, se desparramaron todos. Pero el indio prisionero, como tan práctico de la tierra, insinuaba los parajes a donde ellos pudiesen estar y los pasos por donde podían pasar. Dimos otra vez con ellos en frente del paso de Santo Domingo Soriano. Estuvimos peleando con ellos hasta el anochecer; pero tan a lo lejos, que solamente los de a caballo lograron algunos tiros; y noticiado allí que la caballada estaba cansada, determiné retirarme al paso de Santo Domingo Soriano, por estar cerca y haber agua y pastos. Donde eché menos un español, que se nos agregó y al otro día se topó con su caballo muerto de los infieles. A donde hecha junta de guerra, se determinó pasar a la otra banda a dar descanso a la caballada, pues había agua, pastos y vacas para los soldados; y para el mejor éxito, se determinó el pasar el Reverendo Padre Policarpo Dufo con el Capitán Francisco Saravia; para cuyo efecto se hizo llamada a la gente de Santo Domingo Soriano con fogatas (como se suele) ${ }^{14}$. Quienes luego prontos vinieron con embarcación; y entre ellos aparecieron algunos indios, que antes se habían visto entre los infieles; y preguntados, respondieron que se habían incorporado con ellos, por haber ido acompañando a un fulano Joseph Gómez de Santa Fe, y preguntados, que 
cuando habían pasado a Santo Domingo Soriano? Respondieron que el día antes. Item más preguntados, si habían visto a un español? Respondieron que si, la tarde antecedente, añadiendo a donde y como podían haber muerto. Y se discurre fueron ellos los matadores. Item más preguntados, si habían pasado a la otra banda algunos infieles? Respondieron que no. Con lo cual pasó a la

51 Aires de estas misiones, había el bastante avío para el dicho paraje. Y vuelto el Reverendo Padre Policarpo con el consuelo de haber hallado embarcaciones y alguna carne, para el alimento de los soldados. Con lo cual di providencia para ir pasando luego gente y caballos de la otra banda. Pero los indios tapes y sus Cabos no se consolaban con pasar a la otra banda, alegando no convenía dicho pasaje; porque la caballada estando, como estaba, tan flaca, así como no podía caminar por tierra, tampoco tendría fuerza bastante para pasar a nado río tan anchuroso. Con lo cual determiné de volver para atrás ese mismo día. Y empezada que fue la marcha, los indios de Santo Domingo Soriano tenían ya apartados sus caballos, quienes quedaron hablando con algunos indios nuestros. $Y$ dicen estos que se alababan los indios de Santo Domingo Soriano de haber muerto del Cabo de San Nicolás; y añadieron que ellos habían corrido a dichos indios y flechado a uno de ellos, y quitádoles otra vez los caballos. Los nombres de los indios de Santo Domingo Soriano son estos, Gonzalo, Isidro, Esteban, Fernando, Juan el hijo del indio ticu. El día dos de enero hice general junta de guerra para poder deliberar sobre desistir, o continuar la campaña? Y tomando el parecer de cada uno de los Cabos, fueron uniforme[me]nte de sentir que todos estaban a pie por lo mal tratado de las cabalgaduras, y que en dos o tres meses apenas podrían volver en sí, y habilitarse para la guerra; y que sería consejo más acertado el de retirarse a sus pueblos para en otro tiempo más oportuno, proseguir la empresa ya comenzada. Y habiendo juzgado yo este consejo por el más prudente y acertado, di la vuelta a las Misiones con dolor de mi corazón de no haber perfeccionado la comisión que V Señoría se sirvió de mandarme. Pero siempre con el consuelo de que por mi parte no ha faltado. Y habiendo llegado el día seis de febrero al pueblo de San Joseph, donde se hallaba el Reverendo Padre Superior José Pablo de Castañeda, y noticiándole de todo y de mi disposición de volver a la Campaña, me respondió su Paternidad Reverenda no había posibilidad en los pueblos para aviar tan en breve de mulas y de caballos tan necesarios para los soldados para otra próxima entrada, por haber perecido casi todos en esta Campaña, ya por la falta de pastos, ya de agua, ya por haber comido la pestilencial yerba llamada mio ${ }^{15}$, ya porque en esta Campaña salió lo más florido de las caballadas de los pueblos; y por tanto no ha quedado con que reclutar tan en breve el ejército; y así que nos retiraremos a descansar a nuestra casas, en el ínterin que se solicitaban los medios oportunos y necesarios para otra entrada si V Señoría lo determinase. Y así determiné retirarme con los demás españoles, que traje en mi compañía. Todos hemos venido muy gustosos y agradecidos a los Reverendos Padres, quienes nos han

53 [Folio 7]

54 /atendido con todo amor y cariño, como lo tienen de costumbre. Y no omito en esta ocasión poner en la noticia/ de V Señoría, como todos los indios que llevé en mi Compañía se han portado escogidamente de bien, mostrando su valor, sujeción y rendimiento en cuanto se ha ofrecido y yo les he mandado, sin desmán alguno de ellos, ni conmigo ni con los españoles mis compañeros, ni menos entre sí. Están bien disciplinados 
en el arte militar, obedientes a sus oficiales mayores y menores; portándose en todo como leales vasallos de su Majestad y súbditos de V Señoría. Los dos indios /infieles/ prisioneros y el indio /cristiano/ Ignacio Lezcano /asimismo apresado que años hacía vivía como gentil entre los gentiles/, entregué luego que llegué/ al Reverendo Padre Superior, quien me dijo estarían con todo cuidado y catecismo para bautizar aquellos y casar a este que es cristiano en constando legítimamente ser soltero; mientras que $\mathrm{V}$ Señoría no mandase otra cosa. El indiecito guaranicito murió en el camino antes de llegar a su pueblo. /procurando disponer aquellos para el bautismo y el indio cristiano para el sagrado matrimonio, solicitada la legítima probanza de no estar legítimamente casado, mientras que V Señoría no mandase otra cosa. El guaranicito cautivo del pueblo del Yapeyú, murió antes de llegar a su pueblo en el camino./ Esta es la verdadera noticia de lo sucedido en esta expedición; y como tal lo firmo de mi nombre en dicho día, mes y año. Siendo testigos los que abajo firmaron. Francisco García Piedrabuena. Marcelo Martínez. Francisco Saravia. Juan de Arriola ${ }^{16}$. conste, en este pueblo de San José en doce días de febrero de mil setecientos dieciséis, lo firme de mi nombre.

[rubricado] José Pablo de Castañeda.

\section{BIBLIOGRAPHY}

Acosta y Lara, E. ([1961] 2006). La guerra de los Charrúas. Montevideo: Ediciones Cruz del Sur.

Areces, N. R., López S., Núñez Regueiro, B., Regis, E. y Tarragó, G. (1993). Santa Fe La Vieja. Frontera abierta y de guerra. Los frentes Charrúa y Chaqueño. Memoria Americana, (2), 7-40.

Basile Becker, I. ([1982]2002). Os indios charrua e minuano na Antiga Banda Oriental do Uruguai. São Leopoldo,

R.S., Brasil: UNISINOS.

Bauzá, F. ([1895] 1965). Historia de la dominación española en el Uruguay. Tomo II. Montevideo: Ministerio de Instrucción Pública y Previsión Social.

Bracco, D. (2004). Charrúas, guenoas y guaraníes. Interacción y destrucción en el Río de la Plata. Montevideo: Linardi y Risso.

Cervera, M. (1907). Historia de la ciudad y provincia de Santa Fe 1573-1853. Santa Fe: Imprenta La Unión.

Dufo, P. ([1716] 1870). Informe del P. Policarpo Dufo, sobre lo sucedido en la entrada que se hizo el año de 1715 al castigo de los infieles. Revista del Archivo General de Buenos Aires, (II), 245-261. Buenos Aires: Imprenta El Porvenir.

Latini, S. (2010). Charrúas y minuanes, en busca de sus especificidades étnicas. Actas de las VI Jornadas de Investigación en Antropología Social. Buenos Aires: Facultad de Filosofía y Letras de la Universidad de Buenos Aires. 
López Mazz, J. y Bracco, D. (2010). Minuanos. Apuntes y notas para la historia y la arqueología del territorio guenoa-minuan (Indígenas del Uruguay, Argentina y Brasil). Montevideo: Linardi y Risso.

Nacuzzi, L. (1998). Identidades impuestas. Buenos Aires: Sociedad Argentina de Antropología Nacuzzi, L. (2010). Introducción. En C. Lucaioli y L. Nacuzzi (Comps.), Fronteras. Espacios de interacción en las tierras bajas del sur de América, (pp. 7-19). Buenos Aires: Sociedad Argentina de Antropología.

Sallaberry, J. (1926). Los charrúas y Santa Fe. Montevideo: Gómez Impresores.

Tanodi, B. (2000). Documentos históricos. Normas de transcripción y publicación. Cuadernos de Historia. Serie economía y sociedad, (3), 259-270.

\section{NOTES}

1. Las distintas denominaciones étnicas que aparecen mencionadas en el informe de Piedrabuena fueron analizadas por estudiosos de la historia indígena de la región (Acosta y Lara, [1961] 2006, Basile Bécker, [1982] 2002 y Bracco, 2004). Estos autores abordan la cuestión de la etnicidad desde una perspectiva que considera las territorialidades y las pautas culturales socioeconómicas diferentes como una herramienta esencial para poder diferenciar los diversos grupos étnicos. Escapa a los propósitos del presente trabajo una discusión acerca de la etnicidad, por lo que simplemente referiremos las afirmaciones de los tres autores mencionados para cada etnónimo, a medida que vayan apareciendo en el texto. Para una discusión más completa acerca de esta temática puede verse Latini (2010).

2. Las diferencias pueden presentarse en la grafía o forma en la que el copista escribió las palabras, o en alguna palabra que únicamente se encuentra en alguna de las dos copias. Dichas diferencias son especificadas en la transcripción.

3. El ejército expedicionario partió de la reducción jesuita de Nuestra Señora de los Reyes de Yapeyú el 8 de noviembre de 1715 y regresó al mismo lugar el 23 de enero de 1716. Luego, Piedrabuena continuó su itinerario para encontrarse con el padre superior de los jesuitas que se encontraba en la reducción de San José, y llegó allí el 6 de febrero de 1716.

4. Estos aparecen muchas veces en el texto bajo la denominación de "tapes".

5. Esta edición de la fuente del padre Dufo es la que utilizan todos los investigadores, incluso aquellos que no analizan la campaña de 1715, como Nidia Areces et. al. (1993), Diego Bracco (2004) y José López Mazz y Diego Bracco (2010), porque en dicho documento podemos encontrar varios datos etnográficos del litoral argentino y de las márgenes del río Uruguay, a principios del siglo XVIII.

6. La expresión "tropa" que encontramos en la fuente evoca a un conjunto de hombres que estaba vaqueando, o recogiendo ganado cimarrón. Nosotros optamos por conservar ese sentido o significación del vocablo dentro del texto de análisis; y, para evitar confusión en el lector, diferenciamos el término con que aludimos al ejército español, denominando al mismo como huestes. El ganado vacuno se había multiplicado muy rápidamente en las tierras del Río de la Plata, constituyendo un recurso económico importante para las urbes hispanas. La ciudad de Santa Fe usufructuó el derecho de "vaquería", o recoger ganado cimarrón, en el espacio situado en la otra banda del río Paraná, es decir en la actual provincia argentina de Entre Ríos - territorio habitado por los charrúas-, y en el área localizada al norte de la misma, denominada "Valle Calchaquí". Los accioneros troperos, es decir aquellos autorizados por el cabildo a "vaquear", formaban un contingente con capataces y peones para salir a recoger ganado cimarrón, aunque a veces dejaban estas tareas en manos de terceros (Areces et. al., 1993). Dentro de estas tropas podía haber indios encomendados o algunos "infieles", quienes habrían servido como guías o como 
peones, a cambio de una paga. Esta consistía muchas veces en bienes europeos codiciados por los indios como yerba, tabaco y aguardiente.

7. "Guenoas" era la forma en la que los padres jesuitas describían o nombraban en sus documentos a un grupo étnico que aparece bajo la denominación de minuanes en documentos oficiales españoles y portugueses (Bracco, 2004). Ahora bien, para Eduardo Acosta y Lara los guenoas o minuanes formaban parte tanto étnicamente como culturalmente de un mismo grupo genérico charrúa. "Si bien, charrúas y minuanes figuran como naciones separadas en buena parte del Coloniaje, su destino histórico converge en la segunda mitad del siglo XVIII, pudiendo considerárselos ya fusionados a principios del siglo XIX" (Acosta y Lara, [1961] 2006, p. 25). Mientras que Ítala Basile Becker ([1982] 2002) y Bracco (2004) consideran que los minuanes y los charrúas eran dos grupos étnicos diferentes. Basile Becker en su propósito de diferenciar la etnicidad de charrúas y minuanes utilizó variables como la organización social y las características culturales, lingüísticas y raciales, basándose en la "Guía para Clasificación de Datos Culturales” de George Murdock de 1954. De esta manera arribó a conclusiones como, por ejemplo, que los charrúas no practicaban la agricultura; en cambio, los minuanes cultivaban únicamente la mandioca. Bracco, con un enfoque similar a Basile Becker, nos describe territorialidades y pautas culturales y sociales distintas en charrúas y minuanes. Por ejemplo, menciona que los minuanes "muestran indicios de pautas culturales específicas" y que, a diferencia de los charrúas, eran poligámicos, devinieron en pastores con un reconocimiento de la propiedad individual del ganado y tenían jefaturas con cierta escala jerárquica en grandes extensiones de territorio. Además, "se consideraban a sí mismos diferentes a los nómadas charrúas, con quienes en general mantenían interacción hostil.” (Bracco 2004, p. 89). En el informe de Piedrabuena, que aquí transcribimos, observamos que quince guenoas colaboraron con las huestes españolas en contra de los "indios infieles", ya sea como guías, avanzada del ejército, etc. Sin embargo, esta consideración no es concluyente para señalar que era un grupo étnico diferente. Podría ser una sub-grupo dentro de un grupo étnico mayor - tanto guenoas como charrúa- que respondía a un cacique que estaba en guerra o en relaciones hostiles con los indios a los que Piedrabuena pretendía atacar.

8. Por ejemplo cuando llegan el río Gualeguaychú, Piedrabuena decide dividir sus huestes en tres. Un tercio se quedaría con los caballos cansados y los otros dos marcharían en rumbos diferentes a los parajes de La Centella y Calá respectivamente, adonde le habían dicho que se encontraban tolderías enemigas. Otro ejemplo es cuando deciden torcer el rumbo hacia el río Uruguay en busca de buenos pastos y agua para los caballos.

9. Cuando el ejército expedicionario llegó al paraje de Gena, los guenoas que iban reconociendo el terreno, se toparon con tres indios yaros. Luego de luchar lograron arrestar e interrogar a uno de ellos que identificaron como cacique. Este les dijo que un "español, barbón, amulatado" les había alertado de la marcha de los españoles, y por ello pudieron retirarse antes que estos llegaran.

10. Con respecto a los "yaros" y "bojanes" ("Bojanes" es la forma en la que aparece escrito la mayoría de las veces en la transcripción - una única vez aparece como "Boan" y "Bohan"-, pero todos los estudiosos escriben este etnónimo como "bohanes"), con los que Piedrabuena parlamentó, ambas denominaciones son consideradas como dos parcialidades pertenecientes a los charrúas por Acosta y Lara ([1961] 2006) y Bracco (2004). En cambio, Basile Becker ([1982] 2002) afirma que dichas designaciones se corresponden a una grafía diferente que aparece en las distintas fuentes o papeles coloniales. De esta manera, "yaros" sería un modo distinto de escribir el etnónimo charrúa y "bohanes" el de minuanes. Finalmente, los "machados", a quienes Piedrabuena les dijo que se separasen de los "yaros" y "bojanes", son considerados por López Mazz y Bracco (2010) - de acuerdo a las referencias del informe del jesuita Policarpo Dufo que mencionamos en este trabajo-, como una parcialidad charrúa muy numerosa, preponderante en el sur de Entre Ríos, que generalmente mantuvo buenas relaciones con los españoles. 
11. Cervera (1907) y Sallaberry (1926) estudian el conflicto de intereses entre Santa Fe y Buenos Aires con respecto a las hostilidades contra los charrúas; la primera prefiere detener la campaña punitiva para continuar con las relaciones amistosas con este grupo étnico que ya llevaban varios años, la segunda prefiere proseguir la campaña para defender los intereses de los jesuitas y sus misiones. De esta manera, al mismo tiempo que el cabildo de Santa Fe le envía una carta al gobernador de Buenos Aires pidiéndole que detenga la campaña de Piedrabuena, esta institución comisionó a Esteban Marcos de Mendoza para que salga en búsqueda de las huestes españolas y, una vez localizadas, ordenarle a dicho comandante que posponga las acciones bélicas.

12. En la copia de BNRJ está escrito sin paréntesis.

13. En la copia de BNRJ está escrito sin paréntesis.

14. En la copia de BNRJ está escrito sin paréntesis.

15. En la copia de BNRJ no se encuentra subrayado.

16. En la copia de BNRJ el orden de los nombres es el siguiente: Francisco García Piedrabuena. Marcelo Martínez. Juan de Arriola. Francisco Saravia.

\section{ABSTRACTS}

We present the transcript of the report of the punitive campaign against the "charrúas y demás infieles" carried out by the maestre de campo Francisco García de Piedrabuena in 1715. This manuscript is a copy of the original report written by the commander of the expedition, one of the main protagonists in this campaign, and so far it has not been used by specialists in indigenous history of the region. We also discuss some of the references of this campaign that allow us to contextualize and understand such report. Finally, we make a comparison with another source of the same expedition, written by one of the Jesuit chaplains who accompanied the Spanish forces. We believe that the transcript contains suggestive ethnographic data that permits progress in the knowledge of the ethnic reality of the region.

En este trabajo presentamos la transcripción del informe de la campaña punitiva contra los "charrúas y demás infieles" llevada adelante por el maestre de campo Francisco García de Piedrabuena en 1715. Este manuscrito es una copia del informe original escrito por el propio comandante de la expedición, es decir, uno de los principales protagonistas de la misma, y que, por el momento, no fue trabajado por ningún especialista en historia indígena de la región. Asimismo, comentamos algunas referencias de la mencionada campaña, que permiten contextualizar y comprender mejor el citado informe. Finalmente, realizamos una comparación con otra fuente sobre la misma expedición, escrita por uno de los capellanes jesuitas que acompañaban a las huestes españolas. Consideramos que la transcripción presentada contiene sugestivos datos etnográficos que permiten avanzar en el conocimiento de la realidad étnica de la región.

INDEX

Keywords: Piedrabuena, Charrúas, Indigenous, Report, Punitive campaign

Palabras claves: Indígenas, Informe, Campaña punitiva 


\section{AUTHOR}

\section{SERGIO HERNÁN LATINI}

Universidad de Buenos Aires - Becario doctoral del Consejo Nacional de Investigaciones

Científicas y Técnicas (CONICET), Argentina. Correo electrónico: shlatini@yahoo.com.ar 